\title{
Quantitative analysis of healthy olfactory sulcus depth, olfactory tract length and olfactory bulb volume in the paediatric population: a magnetic resonance study
}

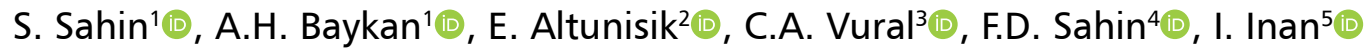 \\ 'Department of Radiology, Adiyaman Education and Research Hospital, Adiyaman, Turkey \\ 2Department of Neurology, Adiyaman Education and Research Hospital, Adiyaman, Turkey \\ ${ }^{3}$ Department of Orthopaedics, Ankara City Hospital, Ankara, Turkey \\ ${ }^{4}$ Department of Paediatrics, Adiyaman Education and Research Hospital, Adiyaman, Turkey \\ ${ }^{5}$ Department of Radiology, Biruni University, Istanbul, Turkey
}

[Received: 4 July 2020; Accepted: 25 September 2020]

Background: The aim of this study was to determine the normal reference values for olfactory sulcus depth, olfactory tract length and olfactory bulb volume in the paediatric population with routine magnetic resonance imaging (MRI) and determine the relationship, if any, between these values and patient sex and age. Materials and methods: Ninety patients with a median age of 8 years (age range: 3-17 years), consisting of 45 males and 45 females with normal brain MRI scans were evaluated. The patients were divided into three subgroups based on age range, with $n=30$ per subgroup; group 1: young children (3-6 years), group 2: children (7-11 years) and group 3: adolescents (12-17 years). In the cranial MRI examination of all groups, the right, left and total olfactory bulb volume values were measured in $\mathrm{mm}^{3}$, the right and left olfactory tract length values and the right and left olfactory sulcus depth values were calculated manually in $\mathrm{mm}$. Demographic data including sex and age were recorded.

Results: There was no significant difference between the age groups in terms of sex. Right-left olfactory sulcus depth; right-left olfactory tract length and right-left total olfactory bulb volume values increased significantly when they are compared in terms of age groups ( $p<0.0001,=0.028 ;<0.0001,<0.0001 ;<0.0001$, $<0.0001 ;<0.0001$, respectively). There was no significant difference between right and left olfactory tract length and olfactory bulb volumes in all groups ( $p=0.792$ and $p=0.478)$, but the right olfactory sulcus depth was significantly larger than the left ( $p=0.003)$.

Conclusions: Especially as the age progresses, olfactory tract length and olfactory bulb volume dimensions of olfactory nerve and olfactory sulcus depth should be checked during diagnosis of respective illnesses in paediatric population. (Folia Morphol 2021; 80, 1: 33-39)

Key words: olfactory sulcus depth, olfactory bulb volume, olfactory tract length, magnetic resonance imaging

Address for correspondence: S. Sahin, MD, Adiyaman Education and Research Hospital, 1164th St., Adiyaman, Turkey, tel: +90 5053941438, e-mail: sukrumirza@gmail.com

The study conducted in Adiyaman Education and Research Hospital. 


\section{INTRODUCTION}

The literature shows that disorders of the olfactory system may be related to many diseases, such as sinonasal disease [14], allergic rhinitis [19], infections [15], trauma [15], epilepsy [8], Behcet's disease [6], migraine [2], idiopathic olfactory loss [15] or disruptions such as gastric excretion in the context of normal digestive physiology [6]. Therefore, determining the anatomical features of olfactory nerve can be very important as it has clinical relevance in the diagnostic process for a clinician.

In this context, the dimensions of olfactory sulcus depth (OSd), olfactory tract length (OTI) and olfactory bulb volume (OBv) can be evaluated radiologically. It has been shown in previous studies that magnetic resonance imaging (MRI) is a reliable method to perform measurements of the olfactory system $[10,11]$. The olfactory system was first defined on MRI by Suzuki et al. [16]. Later, in 1998, the standard OBv measurement method on MRI was developed by Yousem et al. [18]. It is not always possible to visualise OT on MRI $[12,16]$. The measurement of OTI by using MRI was first performed in a 1989 study [16]. The illustration of olfactory structural elements is shown in Figure 1.

In the literature, studies on the structures constituting the olfactory system are mostly focused on the adult population, while radiological studies on the paediatric population are limited. To the extent of our knowledge, there is not any study presenting OBv, OSd, and OTI dimensions in paediatric population extant in the literature. Therefore, this study was planned to determine the normal reference values of these structures by measuring OBv, OSd, and OTI from MRI studies in a healthy paediatric population and to present the findings to the literature.

\section{MATERIALS AND METHODS}

Sample size calculation

G*Power statistical package was used to determine the exact number of cases to be used for analysis. The parameters were determined as follows: effect size $=0.4$, type I error $=0.05$, power $=0.80$, $\mathrm{df}=6$. The total $\mathrm{n}$ number was determined as 92 .

\section{Subjects}

Two hundred eighty-six MRI images were examined at baseline in the present study. One hundred thirty-three images were excluded as they did not meet the inclusion criteria, and 63 images were excluded due to artefacts (Fig. 2). Finally, 90 patients

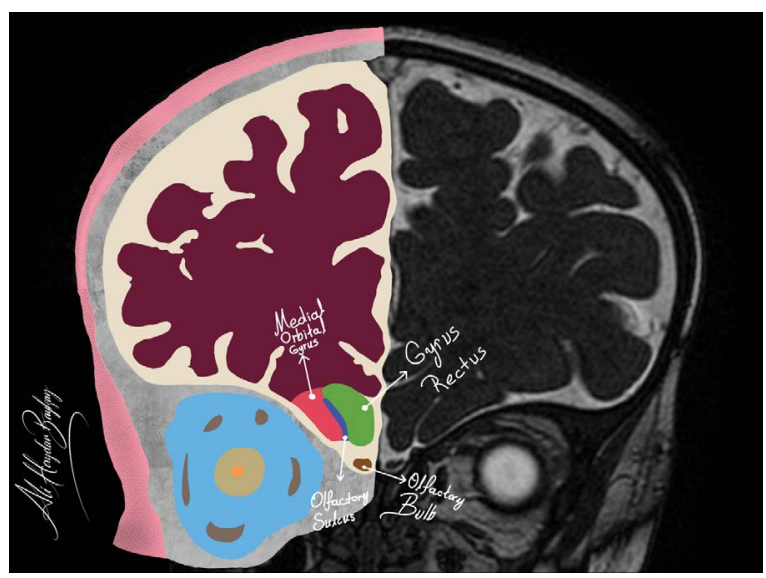

Figure 1. Anatomical radiological image of coronal plane (magnetic resonance imaging). Medial orbital gyrus (red area), gyrus rectus (green area), olfactory sulcus (blue area) and olfactory bulb (brown area) are shown in the illustration side.

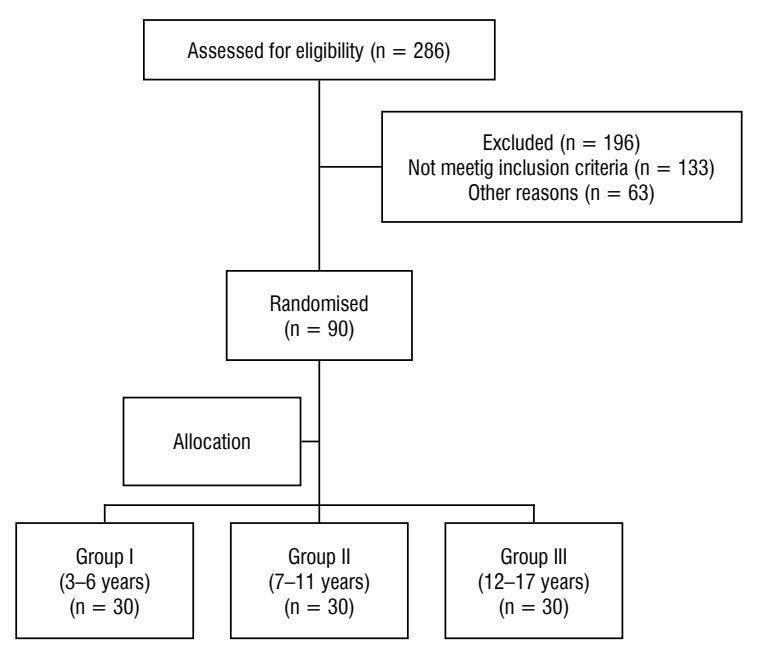

Figure 2. Consort flow diagram.

with MRI images meeting inclusion criteria for normal brain MRI taken from January 2016 to December 2018 were analysed. Patients were considered normal if they had no history of brain trauma, MRI evaluation did not demonstrate sinonasal or brain disease, had no upper respiratory tract infection symptoms; there was no drug use and no environmental exposure that may cause loss of smell. Ethics committee approval was obtained from Adiyaman University Non-Interventional Clinical Research Ethics Board with the number of 2019/1-11. All procedures of this retrospective study were applied according to the principles of the Declaration of Helsinki. "Informed consent" was not obtained from parents as the study was retrospective. Patients included in the study were presented anonymously. The images were obtained retrospectively 
from the archives of the Adiyaman University Faculty of Medicine Department of Radiology.

The clinical evaluation of all subjects included ascertainment of personal and family history as well as physical and neurological examination in order to exclude any possible cause of smell dysfunction. Patients with normal reports for non-enhanced brain MRI were included in the study. Patients with pathologic MRI findings like hydrocephalus, tumour, white matter abnormalities, haemorrhage, infarcts, atrophy and cortical dysplasia that have been treated in hospital were excluded. Metabolic, endocrine, neurological and psychiatric diseases were not included in the study.

Following admission, patients were divided into three groups according to age range as follows: group 1 : young children (3-6 years), group 2: children (7-11 years) and group 3: adolescents (12-17 years).

\section{MRI protocol}

A single radiologist with more than 10 years' experience re-evaluated MRI images. The operator was blinded throughout the procedure until randomisation, in order to avoid possible influence in the measurement process. The MRIs were performed using a 1.5 T system (Achieva; Philips Medical Systems, Best, Netherlands) using a head coil. Contrast material was not utilised. These images were used for volumetric and morphologic measurements. Coronal images, balanced fast-field echo three-dimensional (3D) T2 weighted images (TR: $6.5 \mathrm{~ms}$; TE: $3.4 \mathrm{~ms}$; field of view [FOV] $180 \times 180 \mathrm{~mm}$; number of signal acquisitions [NSA] $=2$; slice thickness $=1 \mathrm{~mm}$; slice gap $=0.5 \mathrm{~mm}$; number of slices $=75$; matrix $=308 \times$ $\times 308 \mathrm{~mm}$ ), sagittal images 3D T1 turbo field echo weighted images (TR: $8.2 \mathrm{~ms}$; TE: $4.0 \mathrm{~ms}$; FOV: $140 \times$ $\times 156 \mathrm{~mm}$; NSA $=4$; thickness $=1.2 \mathrm{~mm}$; slice gap $=$ $=0.5 \mathrm{~mm}$; number of slices $=40$; matrix $=252 \times$ $\times 278 \mathrm{~mm}$ ) were obtained.

\section{Image analysis}

Bilateral OSd, OBv and OTI were measured in all patients. The olfactory bulb was observed as a hypointense ovoid structure surrounded by hyperintense cerebrospinal fluid in T2-weighted series. Sections were obtained at a right angle to the cribriform plate. The volume measurements were obtained semi-automatically using multiplanar reconstructions in a View 3D workstation and manual segmentation based on the contour stack principle. OBv was calculated in $\mathrm{mm}^{3}$ (Figs. 3, 4). OSd was evaluated in coronal T2 weight-

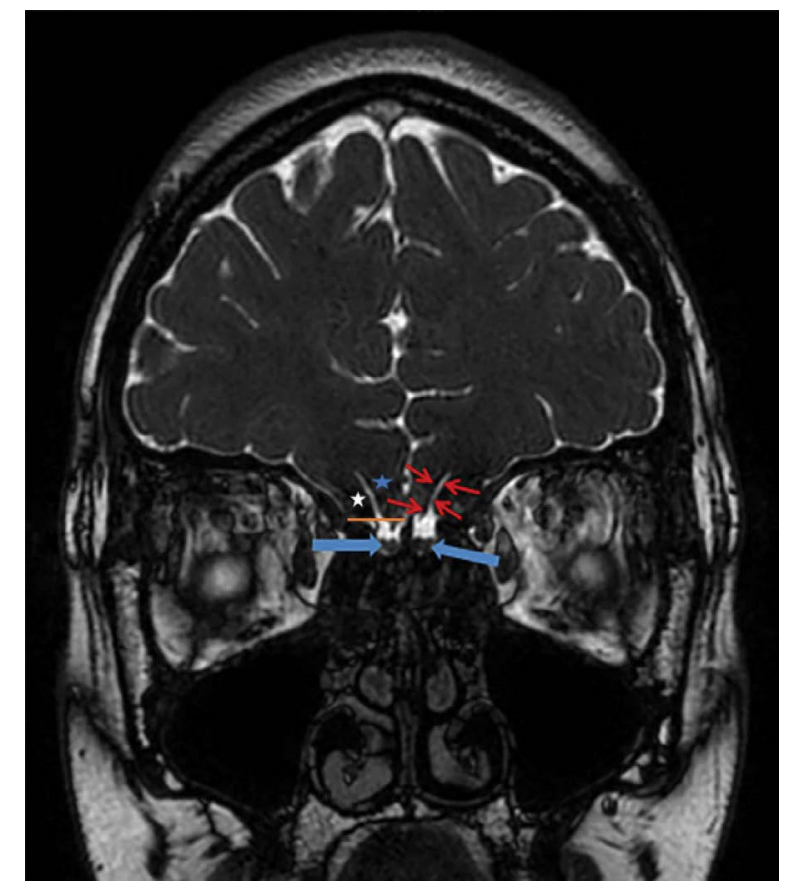

Figure 3. A coronal T2-weighted image showing the right and left olfactory bulb as a hypointense ovoid structure (blue arrows). Hyperintense area (red arrows) (olfactory sulcus) is shown between the medial orbital gyrus (white star) and gyrus rectus (blue star). The virtual line that connects the medial orbital gyrus to gyrus rectus is shown with orange line.

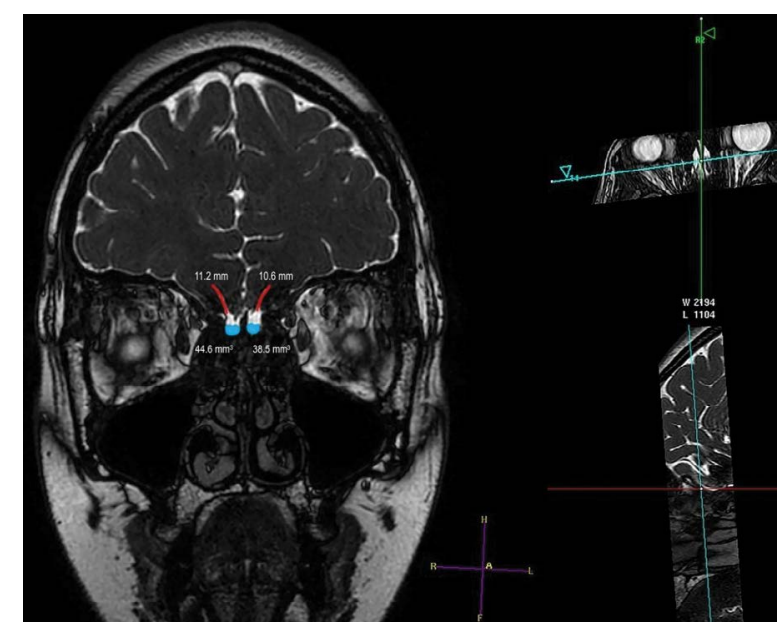

Figure 4. Semi-automatic measurement of the olfactory bulb volume using manual segmentation and multiplanar reformations in the three-dimensional workstation. The olfactory bulb is shown in blue on both sides and the volumes are given in $\mathrm{mm}^{3}$. Olfactory sulcus are shown as red lines and the measurements are given in $\mathrm{mm}$.

ed series. A virtual tangent line was drawn from the lower end of the medial orbital gyrus, connecting to the lower end of the gyrus rectus in the posterior sections of both eyeballs. This virtual tangential line that 


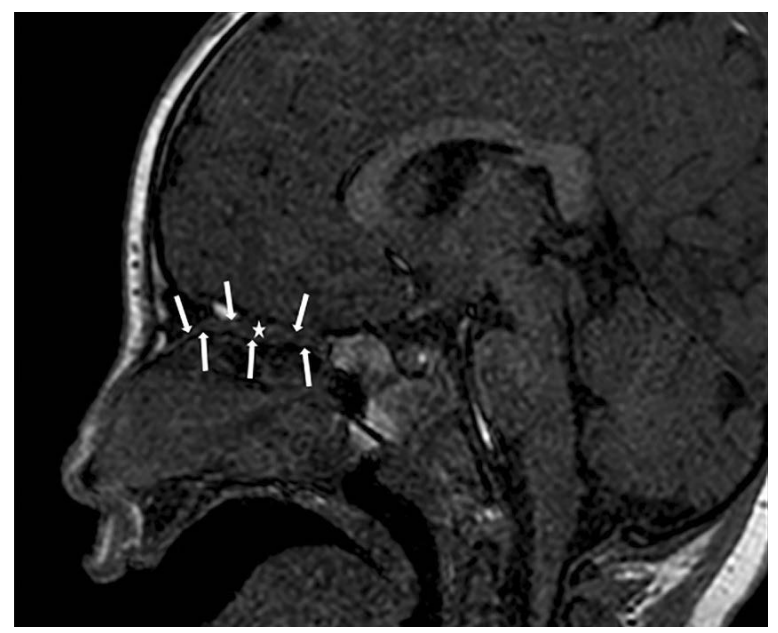

Figure 5. A sagittal T1-weighted image showing the boundaries of the right olfactory tract (white arrows). The mid-portion of the tract is indicated by a star.

passes from the deepest part of the olfactory sulcus was connected by free drawing in the cranio-caudal plane to calculate the depth of the OS and recorded in millimetres (Fig. 4). All the measurements were performed by an individual who was blinded to the patient diagnoses. OTI was measured from the area where the nerve tracing was best visualized on the 3D T1-weighted sagittal images and recorded in mm (Fig. 5). The illustration of olfactory structural elements was performed with the Procreate application (Fig. 1).

\section{Statistical analysis}

SPSS Statistics v. 21.0 (IBM Corp. Released 2012. IBM SPSS Statistics for Windows, Version 21.0. Armonk, NY) software was used for statistical analysis. Categorical data were expressed as number and percentage; nonparametric numeric data were expressed as median, minimum and maximum while parametric numeric data were expressed as mean and standard deviation. The Shapiro-Wilk test was used to evaluate the distribution of numerical data. The Mann-Whitney $U$ was used to evaluate the relationship between sex and OSd and OTI, while Student's t-test was used to evaluate the relationship between sex and OBv. The Kruskal-Wallis test was used to assess the relationship between OSd and OTI in the age groups, and pairwise comparison was used to assess the group that causes the difference in statistically significant patients. The relationship between age groups and $\mathrm{OBv}$ was analysed by the ANOVA test and the Bonferroni test was used to evaluate the pairwise comparisons between the groups.

\section{RESULTS}

A total of 90 patients aged between 3 and 17 years (median: 8 years) were included in the study. Forty-five $(50 \%)$ of the patients were female and $45(50 \%)$ were male. When compared according to age, the right and left OSd and OTI values increased significantly as the mean age increased $(p<0.0001$, $p=0.028$ and $p<0.0001, p<0.0001$, respectively). Right, left and total OBv values increased significantly as the mean age of the group increases. $(p<0.0001$, $p<0.0001, p<0.0001)$. The OSd, OBv and OTI data according to the age group are summarised in Table 1.

No statistically significant relationship was found between OSd, OTI and OBv values in terms of sex (Table 2).

There was no significant relationship between right and left OTI and OBv values when all age groups were included and compared pairwise; while right OSd was found to be significantly increased compared to left ( $p=0.003$ ).

The group that causes the difference was assessed based on pairwise comparisons between the age groups. When the first and third groups were com-

Table 1. Olfactory sulcus depth (OSd), olfactory tract length (OTI) and olfactory bulb volume (OBv) values according to age groups $(n=90)$

\begin{tabular}{|c|c|c|c|c|c|c|c|}
\hline & Right OSd [mm] & Left OSd [mm] & Right OTI [mm] & Left OTI [mm] & Right $\mathrm{OBv}\left[\mathrm{mm}^{3}\right]$ & Left $\mathrm{OBv}\left[\mathrm{mm}^{3}\right]$ & Total OBv $\left[\mathrm{mm}^{3}\right]$ \\
\hline All groups & $\begin{array}{c}8.85 \\
(6-13.6)\end{array}$ & $\begin{array}{c}8.8 \\
(1.8-16)\end{array}$ & $\begin{array}{c}23.95 \\
(16.6-39.8)\end{array}$ & $\begin{array}{c}23.4 \\
(16-39.2)\end{array}$ & $\begin{array}{c}66.15 \\
(32.7-99.6)\end{array}$ & $\begin{array}{c}66.2 \\
(31.8-98.3)\end{array}$ & $\begin{array}{c}133.55 \\
(70-197.9)\end{array}$ \\
\hline $\begin{array}{l}\text { Group I } \\
\text { (3-6 years) }\end{array}$ & $\begin{array}{c}8.45 \\
(6.9-10.8)\end{array}$ & $\begin{array}{c}8.25 \\
(5.1-10.8)\end{array}$ & $\begin{array}{c}20.4 \\
(16.6-28.3)\end{array}$ & $\begin{array}{c}20.85 \\
(16-25)\end{array}$ & $\begin{array}{c}54.7 \\
(33-77)\end{array}$ & $\begin{array}{c}49.3 \\
(31.8-88.8)\end{array}$ & $\begin{array}{c}99.75 \\
(70-152.8)\end{array}$ \\
\hline $\begin{array}{l}\text { Group II } \\
\text { (7-11 years) }\end{array}$ & $\begin{array}{c}8.8 \\
(6-11.3)\end{array}$ & $\begin{array}{c}8.3 \\
(5.5-11)\end{array}$ & $\begin{array}{c}24.3 \\
(18.3-28.7)\end{array}$ & $\begin{array}{c}25.8 \\
(16.7-39.2)\end{array}$ & $\begin{array}{c}66.45 \\
(32.7-84)\end{array}$ & $\begin{array}{c}66.05 \\
(37.8-88)\end{array}$ & $\begin{array}{c}131.65 \\
(77.1-170)\end{array}$ \\
\hline $\begin{array}{l}\text { Group III } \\
\text { (12-17 years) }\end{array}$ & $\begin{array}{c}10.3 \\
(7.5-13.6)\end{array}$ & $\begin{array}{c}9 \\
(1.8-16)\end{array}$ & $\begin{array}{c}25.9 \\
(18.7-39.8)\end{array}$ & $\begin{array}{c}24.45 \\
(19.7-34.6)\end{array}$ & $\begin{array}{c}78.05 \\
(38.3-99.6)\end{array}$ & $\begin{array}{c}78.35 \\
(44.9-98.3)\end{array}$ & $\begin{array}{c}157.6 \\
(83.2-197.9)\end{array}$ \\
\hline$p$ & $<0.0001^{*}$ & $0.028^{*}$ & $<0.0001^{*}$ & $<0.0001^{*}$ & $<0.0001^{* *}$ & $<0.0001^{* *}$ & $<0.0001^{* *}$ \\
\hline
\end{tabular}

*Kruskal-Wallis test; **ANOVA test; data are shown as mean (minimum-maximum) 
Table 2. Olfactory sulcus depth (OSd), olfactory tract length (OTI) and olfactory bulb volume (OBv) values according to sex $(\mathrm{n}=90)$

\begin{tabular}{|c|c|c|c|}
\hline & Male & Female & $\mathbf{P}$ \\
\hline Right OSd [mm] & $8.8(6-12.2)$ & $8.8(6.4-13.6)$ & $0.381^{*}$ \\
\hline Left OSd [mm] & $8.8(1.8-10.8)$ & $8.7(5.6-16)$ & $0.984^{*}$ \\
\hline Right OTI [mm] & $24(17.6-39.8)$ & $23.7(16.6-28.7)$ & $0.103^{*}$ \\
\hline Left OTI [mm] & $23(16-39.2)$ & $23.6(16.8-29.8)$ & $0.904^{*}$ \\
\hline Right $\mathrm{OBv}\left[\mathrm{mm}^{3}\right]$ & $64(32.7-94.5)$ & 67.1 (33-99.6) & $0.656^{* *}$ \\
\hline Left $\mathrm{OBv}\left[\mathrm{mm}^{3}\right]$ & $65.3(33.8-90.1)$ & $72(31.8-98.3)$ & $0.154^{* *}$ \\
\hline Total OBv [mm³] & $128(77.1-184.6)$ & $136(77.1-184.6)$ & $0.324^{* *}$ \\
\hline
\end{tabular}

*Mann-Whitney U Test; ** Student's T-test; data are shown as mean (minimum-maximum)

pared, a statistically significant difference was observed in all values increasing with age. Pairwise comparisons between age groups are presented in Table 3.

Correlation analysis revealed a positive correlation between age and all measurements. Correlation scatter plots are shown in Figure 6.

\section{DISCUSSION}

The evaluation of the olfactory system using MRI has previously been performed in the presence of many diseases, but most studies to date have focused on the adult population [4]. In a study including healthy individuals aged between 19-76 years assessing standard $\mathrm{OBv}$ values, the mean value for right OBv was found to be $41-97 \mathrm{~mm}^{3}$, while the mean value for left OBv was found to be $37-98 \mathrm{~mm}^{3}$ [4]. Buschhuter et al. [4] also emphasized that, the OBv values of males were larger compared to females and the mean decrease with age was equal in both sexes. In the present study, OBv values did not show a significant difference in terms of sex. Rombaux et al. [13] reported the minimum OBv value was $58 \mathrm{~mm}^{3}$ for individuals under 45 years. It was stated that it should be $46 \mathrm{~mm}^{3}$ for over 45 years of age. Yousem et al. [18] stated that $\mathrm{OBv}$ value increased up to $4^{\text {th }}$ decade and decreased with increasing age. Although present study included paediatric age groups, it was found that OBv values increased with age and the results are in parallel with the current literature. Suzuki et al. [16] found that the mean length of the OT was found to be $25 \mathrm{~mm}$. They reported that MRI is an appropriate method for imaging the OT, but it was difficult to evaluate this structure in axial sections [16]. In the present study, OTI measurements were performed on sagittal sections. The current measurement method can be easily applied by physicians in clinical practice, and assessment only takes a short time.

There may be differences between right and left $\mathrm{OBv}$ values in humans. Therefore, measurements are made bilaterally [17]. Since $\mathrm{OBv}$ is a volumetric value, the total OBv value is calculated as the sum of right and left OBv [5]. In our study, a similar method was used: right, left and total OBv values were calculated separately. In a different study, the right OSd was found to be deeper than the left [9]. In addition, some clinical, electrophysiological and neuroimaging studies have emphasized that the right hemisphere has a greater role in the sense of smell than the left hemisphere [9]. The difference between olfactory structural elements found in these studies may be due to the right hemisphere dominance in the olfactory sense. In our study, no significant difference was found between the right and left sides in terms of OBv and OTI values, but the right OSd was significantly deeper than the left. This result can be explained by the fact that the cerebral cortex (medial orbital gyrus and gyrus rectus) forming the olfactory sulcus is more dominant on the right.

In the literature, we did not find any other study in which normal values of these structures were presented by MRI imaging of olfactory structural elements in a healthy paediatric population. In our study, OBv, OSd and OTI values increased significantly with age. This result reflects the neurodevelopmental integrity of all

Table 3. Comparison of age groups with olfactory sulcus depth (OSd), olfactory tract length (OTI) and olfactory bulb volume (OBv) ( $p$ values)

\begin{tabular}{|c|c|c|c|c|c|c|c|}
\hline & Right 0Sd* & Left OSd* & Right OTI* & Left OTI* & Right $\mathrm{OBv}^{* *}$ & Left $\mathrm{OBv}^{* *}$ & Total $0 \mathrm{Bv}^{* *}$ \\
\hline $\begin{array}{l}\text { Group I/Group II } \\
(3-6 \text { y/7-11 y) }\end{array}$ & 1 & 1 & 0.003 & $<0.0001$ & 0.41 & 0.002 & 0.005 \\
\hline $\begin{array}{l}\text { Group I/Group III } \\
(3-6 \text { y/12-17 y) }\end{array}$ & $<0.0001$ & 0.031 & $<0.0001$ & $<0.0001$ & $<0.0001$ & $<0.0001$ & $<0.0001$ \\
\hline $\begin{array}{l}\text { Group II/Group III } \\
(7-11 \text { y/12-17 y) }\end{array}$ & 0.012 & 0.152 & 0.623 & 1 & 0.002 & 0.014 & 0.002 \\
\hline
\end{tabular}

*Pairwise comparison (Kruskal Wallis test); **Post-hoc analysis (Bonferroni correction); $y$ - years 

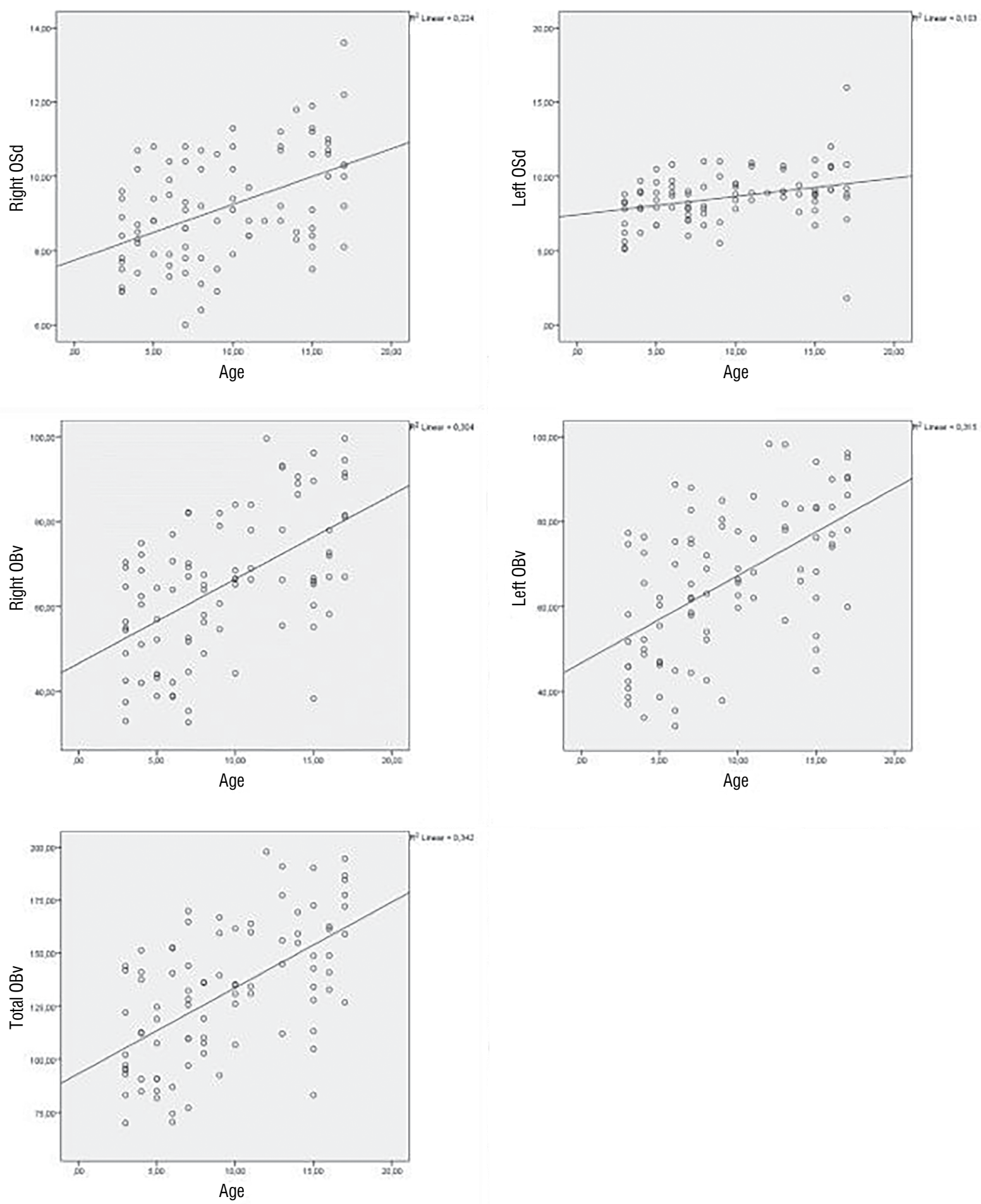

Figure 6. Scatter plots showing the correlation between age and olfactory tract length (OTI), olfactory sulcus depth (OSd), and olfactory bulb volume (OBv).

three structures in the paediatric population. In one study, patients with OSd below $4 \mathrm{~mm}$ did not develop bilateral olfactory bulbs and olfactory tract aplasia [1]. This result also supports neurodevelopmental integrity between these structures. The olfactory sulcus is an anatomical structure formed by the maturation of the medial orbital gyri and gyrus rectus, so the structural elements that make up the olfactory system are not only part of a pure sensory component but can also be a neuroanatomic indicator of cortical function.

$\mathrm{OBv}$ and OSd measurements have been used to structurally evaluate the effect of olfactory system 
in many patients such as isolated congenital anosmia, chronic sinusitis related olfactory dysfunction, post-traumatic, post-infective olfactory dysfunction, epilepsy, migraine, multiple sclerosis, and chemotherapy-related conditions in children [7, 8, 19]. Studies have shown that olfactory structural elements are affected in many of the aforementioned diseases. Most of the diseases and conditions mentioned above are also common in paediatric patients.

Olfactory maturation can give information about cerebral maturation. Hypoplasia and aplasia can be seen in olfactory structures in some diseases such as Kallman syndrome, CHARGE (coloboma, heart defects, choanal atresia, retarded growth and development, genital hypoplasia, ear abnormalities, and/or hearing loss defect) syndrome, and cranio-telencephalic dysplasia $[3,12]$. The olfactory system may be affected by certain diseases such as hypoxic ischaemic encephalopathy, cerebral palsy, some paediatric endocrine and metabolic diseases, and kernicterus. In these diseases, reference values will be needed to evaluate the olfactory system. We hope that our study will contribute to the literature on this matter.

\section{Limitations of the study}

There are some limitations in this study. Olfactory function could not be assessed because of retrospective design. Information about the health of the patients was obtained only from the records. The number of patients in the groups was small in our study. A limitation of this study is the difference between determined and recruited $n$ number of the cases. The total $\mathrm{n}$ number was determined as 92 but only 90 patients were able to access the data. Measurements were performed by a single radiologist and reliability between measurements was not assessed.

\section{CONCLUSIONS}

In conclusion, the present study gives reference values in terms of age-related normal values in children. These normative data can help to evaluate the olfactory sulcus depth, olfactory tract length and olfactory bulb volume in many diseases in children.

\section{Acknowledgements}

The authors wish to express their gratitude to the officers who are responsible from archiving of cases and MRI technician Kasim Tepe.

\section{REFERENCES}

1. Abolmaali ND, Hietschold V, Vogl TJ, et al. MR evaluation in patients with isolated anosmia since birth or early childhood. Am J Neuroradiol. 2002; 23(1): 157-164, indexed in Pubmed: 11827889.

2. Aktürk T, Tanık N, Serin Hi, et al. Olfactory bulb atrophy in migraine patients. Neurol Sci. 2019; 40(1): 127-132, doi: 10.1007/ s10072-018-3597-6, indexed in Pubmed: 30280362.

3. Azoulay R, Fallet-Bianco C, Garel C, et al. MRI of the olfactory bulbs and sulci in human fetuses. Pediatr Radiol. 2006; 36(2): 97-107, doi: 10.1007/s00247-005-0030-0, indexed in Pubmed: 16341529.

4. Buschhüter D, Smitka M, Puschmann S, et al. Correlation between olfactory bulb volume and olfactory function. Neuroimage. 2008; 42(2): 498-502, doi: 10.1016/j.neuroimage.2008.05.004, indexed in Pubmed: 18555701.

5. Chen S, Tan Hy, Wu Zh, et al. Imaging of olfactory bulb and gray matter volumes in brain areas associated with olfactory function in patients with Parkinson's disease and multiple system atrophy. Eur J Radiol. 2014; 83(3): 564-570, doi: 10.1016/j. ejrad.2013.11.024, indexed in Pubmed: 24360232.

6. Doğan A, Bayar Muluk N, Asal N, et al. Olfactory bulb volume and olfactory sulcus depth in patients with Behçet's disease. J Laryngol Otol. 2018 [Epub ahead of print]: 1-5, doi: 10.1017/ S0022215118002141, indexed in Pubmed: 30558688.

7. Doğan $\mathrm{A}$, Bayar Muluk $\mathrm{N}$, Şahan $\mathrm{MH}$, et al. Olfactory bulbus volume and olfactory sulcus depth in migraine patients: an MRI evaluation. Eur Arch Otorhinolaryngol. 2018; 275(8): 2005-2011, doi: 10.1007/s00405-018-5029-x, indexed in Pubmed: 29876641.

8. Hummel T, Henkel $S$, Negoias $S$, et al. Olfactory bulb volume in patients with temporal lobe epilepsy. J Neurol. 2013; 260(4): 1004-1008, doi: 10.1007/s00415-012-6741-x, indexed in Pubmed: 23135292

9. Hummel T, Urbig A, Huart C, et al. Volume of olfactory bulb and depth of olfactory sulcus in 378 consecutive patients with olfactory loss. J Neurol. 2015; 262(4): 1046-1051, doi: 10.1007/ s00415-015-7691-x, indexed in Pubmed: 25712545.

10. Hummel T, Witt M, Reichmann $\mathrm{H}$, et al. Immunohistochemical, volumetric, and functional neuroimaging studies in patients with idiopathic Parkinson's disease. J Neurol Sci. 2010; 289(1-2): 119-122, doi: 10.1016/j.jns.2009.08.026, indexed in Pubmed: 19775703.

11. Kim JiY, Lee WY, Chung EJ, et al. Analysis of olfactory function and the depth of olfactory sulcus in patients with Parkinson's disease. Mov Disord. 2007; 22(11): 1563-1566, doi: 10.1002/ mds.21490, indexed in Pubmed: 17534948.

12. Leboucq N, Menjot de Champfleur N, Menjot de Champfleur S et al. The olfactory system. Diagn Interv Imaging. 2013; 94(10): 985-991, doi: 10.1016/j.diii.2013.06.006, indexed in Pubmed: 23932763.

13. Rombaux $P$, Duprez $T$, Hummel T. Olfactory bulb volume in the clinical assessment of olfactory dysfunction. Rhinology. 2009; 47(1): 3-9, indexed in Pubmed: 19382487.

14. Rombaux Ph, Potier H, Markessis E, et al. Olfactory bulb volume and depth of olfactory sulcus in patients with idiopathic olfactory loss. Eur Arch Otorhinolaryngol. 2010; 267(10): 1551-1556, doi: 10.1007/s00405-010-1230-2, indexed in Pubmed: 20300763.

15. Rombaux Ph, Potier H, Markessis $\mathrm{E}$, et al. Olfactory bulb volume and depth of olfactory sulcus in patients with idiopathic olfactory loss. Eur Arch Otorhinolaryngol. 2010; 267(10): 1551-1556, doi: 10.1007/s00405-010-1230-2, indexed in Pubmed: 20300763.

16. Suzuki M, Takashima T, Kadoya M, et al. MR imaging of olfactory bulbs and tracts. Am J Neuroradiol. 1989; 10(5): 955-957, indexed in Pubmed: 2505540.

17. Wang J, You H, Liu JF, et al. Association of olfactory bulb volume and olfactory sulcus depth with olfactory function in patients with Parkinson disease. Am J Neuroradiol. 2011; 32(4): 677-681, doi: 10.3174/ajnr.A2350, indexed in Pubmed: 21330398.

18. Yousem DM, Geckle RJ, Bilker WB, et al. Olfactory bulb and tract and temporal lobe volumes. Normative data across decades. Ann N Y Acad Sci. 1998; 855: 546-555, doi: 10.1111/j.17496632.1998.tb10624.x, indexed in Pubmed: 9929650.

19. Zhang Q, Liu G, Hang W. [Olfactory bulb volume and depth of olfactory sulcus in patients with allergic rhinitis]. Lin Chung $\mathrm{Er}$ Bi Yan Hou Tou Jing Wai Ke Za Zhi. 2014; 28(24): 1956-1960, indexed in Pubmed: 25895315. 